\title{
Creep behaviour of undisturbed London Clay in triaxial stress space
}

\author{
Truong Le ${ }^{1, *}$, David Airey ${ }^{2}$, and Jamie Standing ${ }^{3}$ \\ ${ }^{1}$ Geolabs Limited; formerly at the University of Sydney \\ ${ }^{2}$ University of Sydney \\ ${ }^{3}$ Imperial College London
}

\begin{abstract}
The evolution of the creep strain component in triaxial stress space was investigated through performing a series of multistage drained compression tests on London Clay using a specially designed locally instrumented triaxial apparatus. Experiments along specifically defined stress paths showed significant rotation of the local creep strain component as the samples were sheared towards failure. The results indicate a need for a more complex plastic potential function to correctly predict incremental creep strains at different states in triaxial stress space. Creep deformations for stress path controlled drained compression tests were also found to require a reinterpretation of the classic secondary compression behaviour. Creep strain-rates were found to fall well outside the normal power decay function. Test data and previously reported drained creep test results on London Clay have been combined to provide a complete understanding of the incremental creep component. The experiments show how creep behaviour significantly depends on the stress conditions imposed and the approaching strain rate.
\end{abstract}

\section{Introduction}

The effects of time on the strength and deformation behaviour of soft and stiff clays have been the focus of numerous investigations over the past few decades. Expanding on the concepts of limit and critical states to describe the behaviour of isotropic normally consolidated clays as originally proposed by Roscoe et al. [1] and Roscoe and Burland [2], a number of other researchers [e.g. 3-5] have also demonstrated the that limit state applies to samples of intact overconsolidated clays. Tavenas [6] has shown that the shape of the limit state surface of a natural clay reflects the stress anisotropy during deposition and consolidation. Assuming that the time dependent framework proposed by Bjerrum [7] could be applied to the entire limit state surface, Tavenas et al. [8] have shown that the volumetric and shear strain components of creep deformations can be described by referring to their position relative to the limit state. Further, the results presented by Leroueil [9] have shown that a general stress-strain-time function may exist which can be expressed in terms of the equation of the limit state surface.

As previously highlighted by Tavenas [6], investigations into the effects of time-dependent behaviour have suffered from two fundamental weaknesses. First, interpretations of soil behaviour have classically separated problems involving stability from problems of settlement. As a consequence, two separate long-term time effects have been defined: creep as related to strength problems (where strength increases with creep) and secondary con- solidation as related to settlement (where settlement further increases after excess pore pressures have dissipated). Further, there is little interconnection between the two phenomena despite their obvious similarities. Second, the problem of creep has primarily been investigated in terms of oedometer test results and therefore principally under one-dimensional conditions. As such, the findings from these investigations are very limited in relation to in-situ scenarios and creep in general stress space.

Regarding the distinction between strength and deformation situations, Tavenas et al. [8] have concluded that the difference between creep and secondary consolidation is mostly artificial. Combining the concept of the limit state with the observed time effects, Tavenas et al. [10] have shown that the entire limit state surface of a natural, undisturbed clay is age and rate dependent. That is, when loading an overconsolidated aged clay, the measured preconsolidation pressure will be a function of $(a)$ the age of the clay and $(b)$ the duration of loading, increasing proportionally with the rate of loading or strain rate.

A number of researchers have suggested that aspects of time-dependent phenomena, i.e., volumetric and shear deformations, strength variation and change in preconsolidation pressure are a result of a unique physical process and should therefore be captured in a single framework [e.g. 8-11]. Starting with the classical assumption that time dependent deformations, expressed as an increment of void ratio, $\Delta e$, develop according to a function of the form

$$
\Delta e=C_{\alpha} \log \frac{t_{i}+t}{t_{i}}
$$

*e-mail: tle@geolabs.co.uk 
where $C_{\alpha}$ is the coefficient of secondary consolidation and assumed to be a constant, $t_{i}$ is the origin of time and $t$ is time. This was later extended to the 'secondary consolidation' approach to model the development of volumetric and axial strains with time, with the equation taking the form

$$
\varepsilon_{1}=v=\frac{C_{\alpha}}{1+e_{0}} \log \frac{t_{i}+t}{t_{i}}
$$

where $\varepsilon_{1}$ is strain measured in the vertical direction, $v$ is the volumetric strain and $e_{0}$ is the initial void ratio. The application of secondary consolidation to simulate in-situ conditions has, however, been complicated due the reported variation of $C_{\alpha}$ with applied stress and time [e.g. $12,13]$. Alternatively, the 'creep' approach has resulted in a general phenomenological equation for the variation of axial strain rate, $\dot{\varepsilon}$, with deviatoric stress, $q$, and time [14]. The creep equation typically takes the form

$$
\dot{\varepsilon}=A e^{\overline{\alpha q}}\left(\frac{t_{1}}{t}\right)^{m}
$$

where $A$ is a parametric constant and $\overline{\alpha q}$ is a stress dependent creep function. In both approaches, strains vary with the logarithm of time. This therefore requires an arbitrary definition of the origin for time, $t_{i}$. It is common for the origin of time to be taken as equal to end-of-primary consolidation in Equation (2) and 1 day in Equation (3). A major difficulty with both these approaches has been in problems that involve applied loads that vary with time. In such cases, both the origin of time and change in effective stress are not obvious.

Rheological models of the forms

$$
\begin{aligned}
R\left(\sigma_{v}^{\prime}, e, \dot{\sigma}_{v}, \dot{e}\right) & =0 \\
R\left(\sigma_{v}^{\prime}, e, \dot{e}\right) & =0
\end{aligned}
$$

have been formulated to overcome the difficulty of an origin of time by describing the behaviour of a material so that it depends only on its present condition and not as a function of previous history [9]. Such models are equivalent to the 'isotache concept' first suggested by Šuklje [15] as the rate of volumetric deformations are a unique function of the void ratio and the effective stress. Tavenas et al. [8] demonstrate how the concept of isotaches can be expanded to apply to all strain tensors in general stress space. Tavenas et al. [8] therefore argue that isotache curves can be associated with a limit state such that there are bounding surfaces of constant $\dot{\varepsilon}$ in the $e-q-p^{\prime}$ space.

The purpose of this paper, following a brief summary of the existing literature on time-dependent deformation in stress space, is to present the results from a series of long-term triaxial tests on undisturbed London Clay. Discussion focuses on the viscous behaviour of soil during a multi-stage creep test in order to review the existing understanding of time-dependent phenomena in overconsolidated clays.

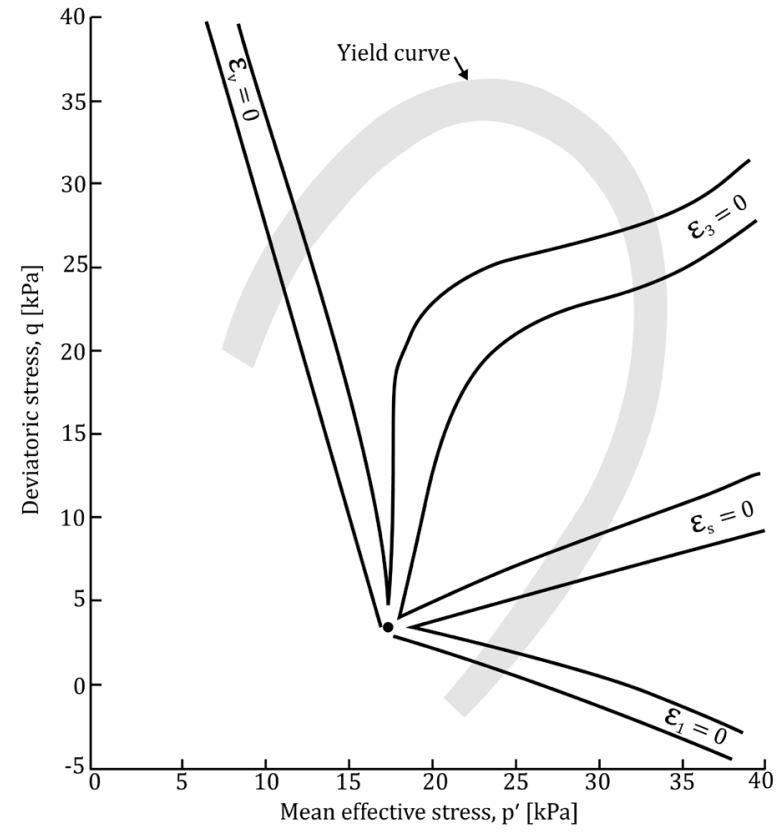

Fig. 1. Stress conditions for which $\varepsilon_{\mathrm{v}}, \varepsilon_{1}, \varepsilon_{3}, \varepsilon_{s}$ are zero, as obtained from stress controlled tests on an undisturbed lightly overconsolidated clay (modified from[8])

\section{Time-dependent deformations in general stress space}

As is typical in soil mechanics, stress and strain variables are separated into compression-change of size-and distortion-change of shape. For axisymmetric conditions of the triaxial test, mean effective octahedral stress $p^{\prime}=$ $\left(\sigma_{a}^{\prime}+2 \sigma_{r}^{\prime}\right) / 3$ and deviatoric stress $q=\left(\sigma_{a}^{\prime}-\sigma_{r}^{\prime}\right)$, and the corresponding work-conjugate strain increments: volumetric strain $\delta \varepsilon_{p}=\delta \varepsilon_{a}+2 \delta \varepsilon_{r}$ and distortional strain $\delta \varepsilon_{q}=2\left(\delta \varepsilon_{a}-\delta \varepsilon_{r}\right) / 3$ are used to describe conditions of stress and strain in soils.

In triaxial stress space, Tavenas et al.[10] have shown that there are zones for which different strain components become zero. Figure 1 shows an example of the various stress conditions that result in a zero strain component [10].

By considering the use of strain energy as an indicator for yielding of lightly overconsolidated clays, Tavenas et al. [10] found that it was necessary to integrate all components of the strain tensor to describe the stress-strain behaviour. Consequently, it was found that a 'threshold energy level' assumes a similar shape to those of the limit state surface. In a triaxial test, the strain energy $W$ dissipated can be expressed as

$$
\begin{aligned}
W=\sum\left\{\left[\frac{\sigma_{a i}^{\prime}+\sigma_{a(i+1)}^{\prime}}{2}\right]\left[\varepsilon_{a(i+1)}-\varepsilon_{a i}\right]\right. \\
\left.+2\left[\frac{\sigma_{r i}^{\prime}+\sigma_{r(i+1)}^{\prime}}{2}\right]\left[\varepsilon_{r(i+1)}-\varepsilon_{r i}\right]\right\}
\end{aligned}
$$

The volumetric and shear component of strain energy being respectively, 


$$
\begin{aligned}
& W_{\mathrm{v}}=\sum \frac{p_{i}^{\prime}+p_{(i+1)}^{\prime}}{2}\left[v_{(i+1)}-v_{i}\right] \\
& W_{\mathrm{s}}=\sum \frac{q_{i}+q_{(i+1)}}{2}\left[\varepsilon_{(i+1)}-\varepsilon_{i}\right]
\end{aligned}
$$

In more general cases of triaxial loading, the strain energy can be written in the form

$$
W=\int \frac{p^{\prime} d p^{\prime}}{\mathbf{K}}+\int \frac{q d q}{3 \mathbf{G}}
$$

where $\mathbf{K}$ is the bulk modulus and $\mathbf{G}$ is the shear modulus.

During creep, the dissipation of strain energy with time has been reported to be similar to that of the measured volumetric, axial and shear strain rates [10]. That is, the logarithm of the rate of energy dissipation decreases linearly with the logarithm of time. The expression for the dissipation of strain energy therefore takes a function of the form

$$
W=\Omega\left(\frac{t_{1}}{t}\right)^{m}
$$

where $\Omega$ is a creep stress function. It is should be apparent that the strain energy dissipation equation is of the same form as Equation (3). The effect of stress path on the rate of dissipation of strain components was investigated by Tavenas et al. [10]. The stress conditions under which creep tests were carried out are shown in Figure 2. It was found that for an incrementally loaded test on a lightly overconsolidated clay, the creep parameter $m$ varies between 0.6 and 0.82 , where the value of $m$ decreases with increasing shear stress. Tavenas et al. [8] found that while the classical approach to volumetric creep predicts the parameter $m$ should be equal to 1 , the lower values of $m$ are associated with a primary consolidation phenomenon. Further, Tavenas et al. [8] suggested that the higher values of $m$ are associated with the lower stress levels, reflecting the perfectly linear $\log \dot{\varepsilon}-\log t$ where negligible effects of primary consolidation were experienced by the sample.

At higher stress levels, Tavenas et al. [8] found $\log \dot{\varepsilon}$ to decrease initially, reach a minimum strain rate and then rapidly increase until failure. The latter phenomenon is also known as creep rupture, although this is more commonly encountered in undrained creep tests where pore pressures continuously develop until the stress state approaches failure from the right of the critical state line.

In defining the stress-strain rate relationship, such as in Equation (3), Tavenas et al. [8] plotted the various components of the strain tensor in terms of equal strain rates throughout the triaxial stress space. As shown in Figure 2, lines of equal volumetric strain rate are plotted in red and lines of equal shear strain rate are plotted in blue. From Figure 2, it follows that a large area of the stress space, between lines 4 and 5, correspond to very small or zero volume change. In the same space, lines of constant shear strain rate were found to be approximately parallel to the

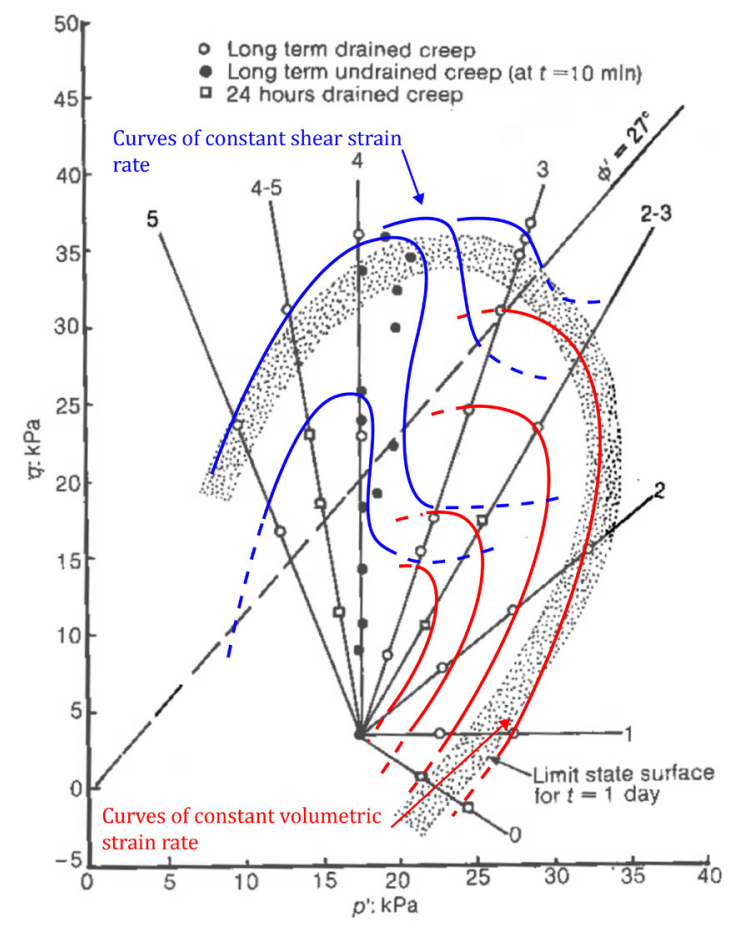

Fig. 2. Stress conditions applied in creep test on a lightly overconsolidated clay (modified from [8])

limit state surface. Tavenas et al. [8] therefore suggested that the limit state surface would be related to both the volumetric and shear strain rate components. It first appears as if the transition between homothetic curves of volumetric and shear strain rate occurs at conditions of constant radial effective stress, line 3 . Recent discussions on the incremental strain component [e.g. 16] have shown that loci of constant volumetric strain rate can be assumed for stress levels up to approximately $0 \cdot 6 M$, where $M$ is the critical state stress ratio.

\section{Experimental programme}

The test programme was carried out on samples of undisturbed London Clay from Hyde Park, London. All samples were selected from similar depths, $26.40-29.80 \mathrm{~m}$, and of the same geological formation, Division $\mathrm{B}_{2}$ [17]. A total of four $70 \mathrm{~mm}$ dia. samples were tested in special triaxial apparatus designed to investigate long-term creep effects. Descriptions of the apparatus can be found in Abdalla and Sim [18] and Le [19]. Table 1 summarises the index properties of the clay from Hyde Park.

Following set-up and an undrained saturation stage, all samples were reconsolidated isotropically back to the approximate in-situ mean effective stress. As all samples were from very similar depths, a common initial isotropic stress was selected. From this origin, four different stress paths were followed until drained failure of the sample. Along each stress path, target stresses were achieved using computer control. Shearing was performed at sufficiently low stress rates $(1 \mathrm{kPa} / \mathrm{hr})$ so as to not generate excess pore pressure. At predetermined stress states along the spec- 
Table 1. Index property of London Clay at Hyde Park

\begin{tabular}{cccccc}
\hline Borehole & $\begin{array}{c}\text { Depth } \\
\text { below G.L. }\end{array}$ & $\begin{array}{c}\text { Water } \\
\text { content [\%] }\end{array}$ & $\begin{array}{c}\text { Liquid } \\
\text { Limit [\%] }\end{array}$ & $\begin{array}{c}\text { Plastic } \\
\text { Limit [\%] }\end{array}$ & $\begin{array}{c}\text { Specific } \\
\text { Gravity }\end{array}$ \\
\hline BH03 & $28.20 \mathrm{~m}$ & 24.5 & 70 & 30 & 2.75 \\
BH09 & $26.60 \mathrm{~m}$ & 23.7 & 73 & 30 & 2.77 \\
BH09 & $29.80 \mathrm{~m}$ & 25.8 & 75 & 27 & 2.74 \\
\hline
\end{tabular}

Table 2. Properties London Clay from Division $\mathrm{B}_{2}$ and summary of creep test conditions

\begin{tabular}{cccc}
\hline Test Number & Stage & $\begin{array}{c}\text { Stress path } \\
\Delta q / \Delta p^{\prime}\end{array}$ & $\begin{array}{c}\text { Creep stress } \\
p^{\prime}, q[\mathrm{kPa}]\end{array}$ \\
\hline LC1 & C1 & 15.6 & $444.2,12.6$ \\
& C2 & & $446.4,62.7$ \\
& C3 & & $455.5,198.8$ \\
& C4 & & $458.1,248.2$ \\
& C5 & & $464.2,346.8$ \\
LC2 & C1 & 6.12 & $450.7,51.4$ \\
& C2 & & $458.9,102.8$ \\
& C3 & & $469.5,164.0$ \\
& C4 & & $475.9,204.9$ \\
& C5 & & $489.6,285.9$ \\
LC3 & C6 & & $500.8,355.0$ \\
LC4 & C1 & 4.69 & $510.5,321.4$ \\
\hline
\end{tabular}

ified stress path, stages of constant stress were defined; stages of constant stress were held for a minimum of 1000 mins. Table 2 summarises applied stress path and creep stress states for each of the four tests. Throughout shearing, axial and radial deformations were directly measured using local instrumentation. Volumetric and shear strains were calculated from measured local displacements.

\section{Creep behaviour of London Clay}

\subsection{Creep strain increment}

Departing from the artificial distinction between secondary consolidation and creep, the present investigation has more generally considered the time-dependent development of volumetric and shear strains in heavily overconsolidated London Clay under a narrow yet relatively unexplored range of stress conditions. The current study aims to investigate more closely the stress space between constant $\sigma_{3}^{\prime}$ drained compression and constant $\sigma_{1}^{\prime}$ drained compression as a detailed study of the time-dependent behaviour of London Clay along constant $\sigma_{3}^{\prime}$ drained compression and constant $\sigma_{1}^{\prime}$ drained compression have already been explored by Lovenbury [20].

Generally, the drained shearing behaviour of London Clay was typical of a heavily overconsolidated soil and was found to be consistent with reported results [21]. From an isotropic state well below the yield stress, the shearing behaviour of London Clay along each defined stress paths was found to be generally elastic with minimal volumetric strains until the stress state exceeded the critical state stress ratio after which the overconsolidated nature of the clay led to the sample demonstrating significant dilation. Following the peak shear stress, the samples exhibited strain softening with localisation of the strains being associated with the formation of a distinct shear plane. Figure 3 show total accumulated volumetric and shear strains for the four samples of London Clay with time.

During stages of constant stress, all specimens showed trends in time-dependent behaviour that were consistent with the material's stress state and geological history (overconsolidated nature). Figure 4 plots the ratio of incremental viscous strain components for London Clay in stress space during the various creep stages. The behaviour was found to be consistent with that presented by Tavenas et al. [8] and [10]. At stress ratios less than $0 \cdot 2 M$, little to no volumetric and shear deformations were measured after an extended period of time; where viscous strains were measured, volumetric deformations were found to dominate. With continued increase in deviator stress, where the stress ratios were between $0 \cdot 2 \mathrm{M}$ and $1.0 M$, total measured shear strains were found to increase during drained compression. Subsequently, timedependent shear strains were found to increasingly contribute to the total viscous deformation. The increase in viscous strain during stages of constant stress and total contribution of shear strain can be seen in Figure 4 through (a) the counter-clockwise rotation of the viscous strain vector as the stress state approaches the peak stress ratio and $(b)$ the relative increase in strains measured during the stage.

Creep compression tests along constant $\sigma_{3}^{\prime}$ drained compression and constant $\sigma_{1}^{\prime}$ drained compression for London Clay from Lovenbury [20] are also included in Figure 4 for completeness. Combining the results found for London Clay with those presented by Tavenas et al. [8], both of which study the creep behaviour of overconsolidated clays, it can be said that the incremental viscous strain vector rotates towards the direction of the stress path until drained failure where shear strains completely dominate. Similar to the conclusion presented by Freitas et al. [16], it was found that significant rotation of the viscous strain increment towards the vertical did not occur until the stress state exceeded approximately $q / p^{\prime}>0 \cdot 6 \mathrm{M}$.

\subsection{Strain development with time}

While a number of researchers have shown that the viscous behaviour of a clay is essentially governed by the relative position of the stress state to the limit state surface [e.g. 8, 14], recent studies have revealed a more complex strain-rate relationship with time than was suggested in either Equations (2) or (3) [e.g. 22, 23]. More specifically, 


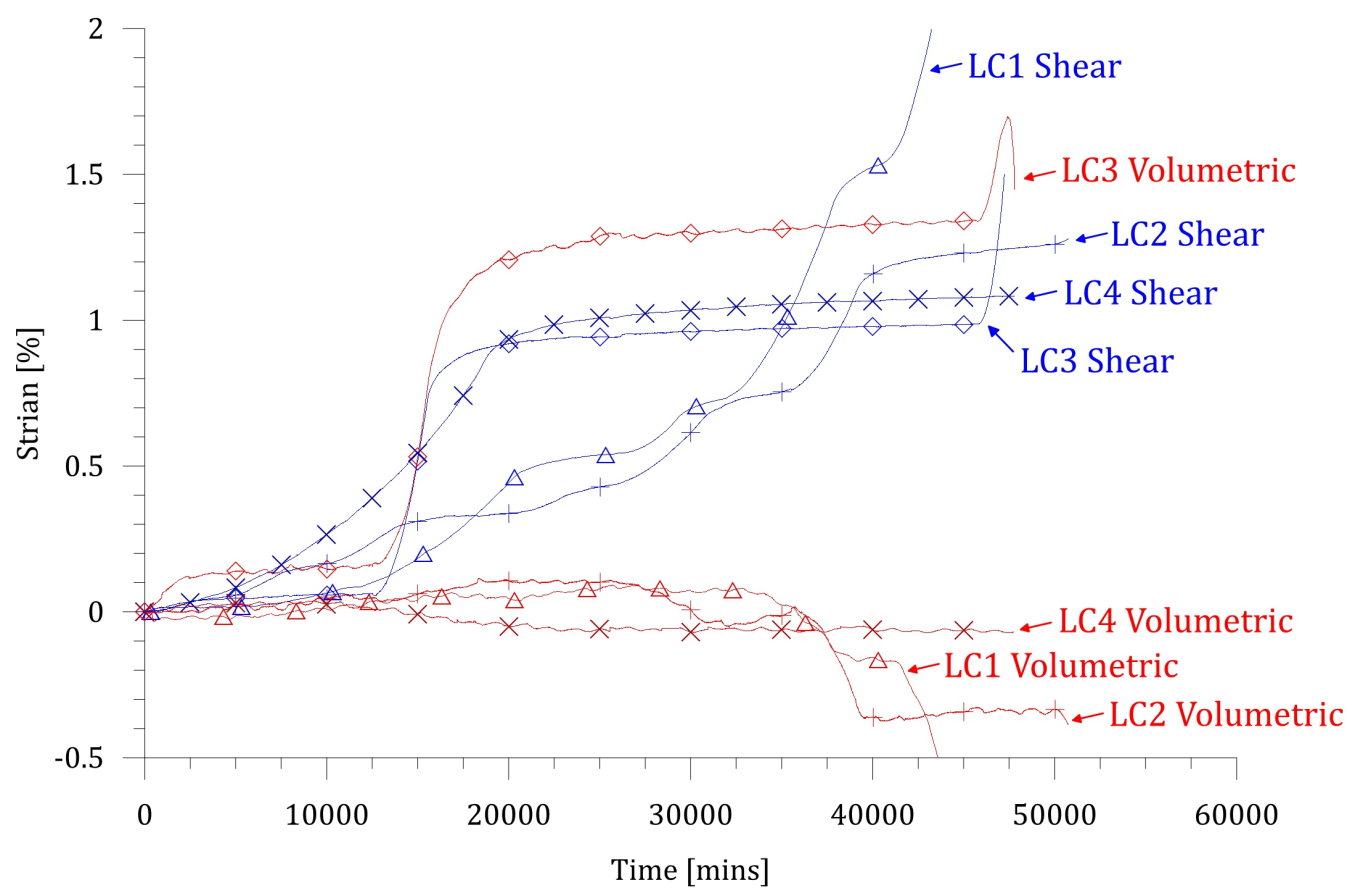

Fig. 3. Total accumulated volumetric and shear strain with time for creep tests on London Clay

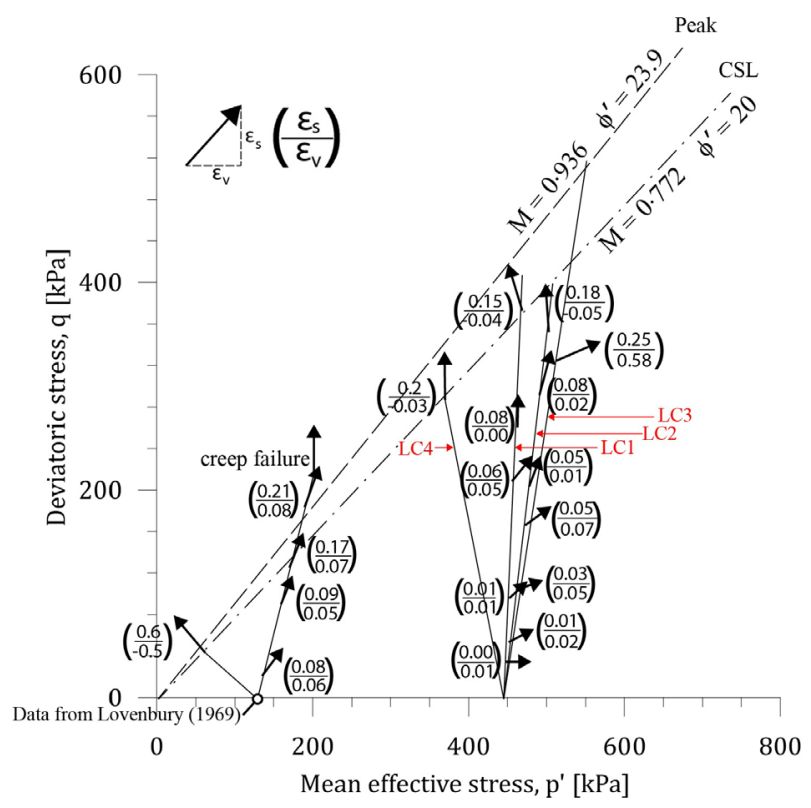

Fig. 4. Ratio of incremental creep strain components for London Clay in $p^{\prime}-q$ stress space

recent findings have indicated that $(a)$ Equation (2) often inaccurately captures viscous deformations as an origin of time must be defined, and $(b)$ the creep parameter $m$ in Equation (3) does not appear to be a material constant and varies with stress level and interacts with the primary consolidation phenomenon, as discussed earlier.
Stages of constant stress during stress-rate defined loading on London Clay have revealed strain-rate-time behaviour that is not captured by either Equations (2) or (3). Additionally, the origin of time required for Equation (2) was unclear as no primary consolidation occurs during a drained compression test; the curve fit during constant stress was therefore inadequately predicted by the secondary consolidation approach. Rather than the typical power decay function predicted by either Equation (3) or (10), a significant period of constant strain-rate was observed at the start of constant stress state stages. Similar to the results presented by Kuwano and Jardine [23], creep tests on London Clay found significant interaction between the approaching strain-rate and the measured strainrate-time decay function. That is, the rate of strain-rate decay (represented by parameter $m$ ), was significantly affected by the measured strain-rate as a result of the sample's tendency to deform. It was found that as the stress state approached the limit state surface, increased sample deformation resulted in a higher slope of $m$. This result contradicts the conclusion presented by Tavenas et al. [10] where $m$ was found to decrease with increasing stress level.

This discrepancy is, however, resolved by examining the different modes of shearing. Whereas stress states were achieved by applying incremental loads by Tavenas et al. [10] and [8], stress states in this investigation were achieved using computer controlled stress-rate defined loading in this investigation. The difference in achieving the required stress state is believed to affect significantly the approaching strain-rate and therefore the observed creep rate behaviour. As a result of the difference, 
it is suggested that the creep parameter $m$ is also a function of testing technique and should be considered carefully before accepting the parameter as a characteristic property.

The observed strain-rate behaviour can also be understood in terms of the 'isotache concept' as the creep strainrate is a function of the approaching strain rate, such as given by Equations (4) or (5)

\section{Conclusion}

The laboratory testing programme carried out on four undisturbed samples of heavily overconsolidated London Clay gave insight into the time-dependent behaviour of clays in stress space. The main conclusions of this study may be summarised as follows.

- The incremental viscous strain component was found to be a function of the stress state in triaxial stress space.

- Along defined compression stress paths, the viscous strain vector was found to rotate counter clock-wise towards the vertical (critical state).

- No significant rotation of the viscous strain vector was noted until the stress state exceeded approximately $q / p^{\prime}>0.6 M$.

- Both the Singh and Mitchell [14] strain-rate decay and the dissipation of energy functions were found to overestimate the strain-rate-time behaviour observed for stress-rate defined loading on London Clay.

- Significant time delay was found at the onset of constant stress before strain-rate decreased as described in either of the strain-rate-time functions.

- The secondary consolidation approach did not adequately describe the time-dependent behaviour due to the absence of primary consolidation.

\section{References}

[1] K.H. Roscoe, A. Schofield, C. Wroth, Géotechnique 8, 22 (1958)

[2] K. Roscoe, J. Burland, On the generalized stressstrain behaviour of wet clay (Cambridge University Press, 1968)

[3] J. Crooks, J. Graham, Géotechnique 26, 293 (1976)

[4] R.J. Mitchell, Canadian geotechnical journal 7, 297 (1970)

[5] J. Graham, J. Crooks, A. Bell, Géotechnique 33, 327 (1983)

[6] F. Tavenas, Effects of stresses and time on the yielding of clay, in Proceedings of the 9th ICSMFE (1977), Vol. 1, pp. 319-326

[7] L. Bjerrum, Géotechnique 17, 83 (1967)

[8] F. Tavenas, S. Leroueil, P.L. Rochelle, M. Roy, Canadian Geotechnical Journal 15, 402 (1978)

[9] S. Leroueil, M. Kabbaj, F. Tavenas, R. Bouchard, Géotechnique 35, 159 (1985)

[10] F. Tavenas, J.P. Des Rosiers, S. Leroueil, P. La Rochelle, M. Roy, Géotechnique 29, 285 (1979)
[11] F. Tatsuoka, T. Uchimura, K. Hayano, H. Di Benedetto, J. Koseki, M. Siddiquee, Timedependent deformation characteristics of stiff geomaterials in engineering practice, in Proceedings of 2nd International Conference on Pre-failure Deform. Charact. of Geomat (2001), Vol. 2, pp. 1161-1262

[12] G. Mesri, T. Stark, C. Chen, Journal of Geotechnical Engineering-ASCE 120, 764 (1994)

[13] G. Mesri, A. Castro, Journal of Geotechnical Engineering 113, 230 (1987)

[14] A. Singh, J.K. Mitchell, Journal of the Soil Mechanics and Foundations Division 94, 21 (1968)

[15] L. Šuklje, The analysis of the consolidation process by the isotaches method, in Proceedings of the 4th International Conference on Soil Mechanics and Foundation Engineering, London (1957), Vol. 1, pp. 200206

[16] T.B. Freitas, D. Potts, L. Zdravkovic, Géotechnique 62, 643 (2012)

[17] C. King, The stratigraphy of the London Clay and associated deposits (Backhuys, 1981)

[18] K.A. Abdalla, W.W. Sim, Effect of Time on the Evolution of Soil Behaviour: New Advanced Triaxial Creep Cell Experiments, in Geotechnics for Sustainable Infrastructure Development (2016)

[19] T. Le, Ph.D. thesis, University of Sydney (2018)

[20] H.T. Lovenbury, Ph.D. thesis, Imperial College of Scienceand Technology (1969)

[21] A. Gasparre, Ph.D. thesis, Imperial College London (2005)

[22] G. Imai, Y. Tanaka, H. Saegusa, Soils and Foundations 43, 173 (2003)

[23] R. Kuwano, R.J. Jardine, Canadian Geotechnical Journal 39, 1061 (2002) 